\title{
Clinical spectrum of COVID-19 and risk factors associated with severity in Spanish children
}

\author{
Alfredo Tagarro ${ }^{1,2,3}$ - Elena Cobos-Carrascosa ${ }^{2} \cdot$ Serena Villaverde $^{2} \cdot$ Francisco-Javier Sanz-Santaeufemia $^{4}$. \\ Carlos Grasa $^{5}$ - Antoni Soriano-Arandes ${ }^{6}$. Alicia Hernanz ${ }^{7}$. María Luisa Navarro ${ }^{7}$. Rosa Pino ${ }^{8}$. Cristina Epalza ${ }^{2,9}$. \\ Rosa Batista ${ }^{1}$. Jana Rizo ${ }^{1}$. María-Isabel Iglesias-Bouzas ${ }^{10}$. Paula Rodríguez-Molino ${ }^{5}$ Sara Villanueva-Medina ${ }^{9}$. \\ Jaime Carrasco-Colom ${ }^{9}$. José-Antonio Alonso-Cadenas ${ }^{4}$. María-José Mellado ${ }^{5}$. Blanca Herrero ${ }^{4}$. \\ Susana Melendo ${ }^{6} \cdot$ Mercedes De La Torre $^{4} \cdot$ Lourdes Calleja $^{4} \cdot$ Cristina Calvo $^{5} \cdot$ María Urretavizcaya-Martínez $^{11}$. \\ Itziar Astigarraga ${ }^{12} \cdot$ Ana Menasalvas $^{13} \cdot$ María Penin $^{14}$. Olaf Neth ${ }^{15}$. Arantxa Berzosa ${ }^{16}$. María De Ceano-Vivas ${ }^{17}$. \\ Paula Vidal $^{18}$ - Isabel Romero ${ }^{19} \cdot$ Raúl González $^{20}$ - María Luz García ${ }^{21}$ - Juan-Miguel Mesa ${ }^{1}$ - Álvaro Ballesteros ${ }^{2}$. \\ María Bernardino ${ }^{1}$. Cinta Moraleda ${ }^{2,9} \cdot$ EPICO-AEP Working Group
}

Received: 12 August 2021 / Revised: 6 October 2021 / Accepted: 28 October 2021 / Published online: 5 November 2021 (c) The Author(s), under exclusive licence to Springer-Verlag GmbH Germany, part of Springer Nature 2021

\begin{abstract}
We aimed to identify the spectrum of disease in children with COVID-19, and the risk factors for admission in paediatric intensive care units (PICUs). We conducted a multicentre, prospective study of children with SARS-CoV-2 infection in 76 Spanish hospitals. We included children with COVID-19 or multi-inflammatory syndrome (MIS-C) younger than 18 years old, attended during the first year of the pandemic. We enrolled 1200 children. A total of $666(55.5 \%)$ were hospitalised, and $123(18.4 \%)$ required admission to PICU. Most frequent major clinical syndromes in the cohort were mild syndrome (including upper respiratory tract infection and flu-like syndrome, skin or mucosae problems and asymptomatic), 44.8\%; bronchopulmonary syndrome (including pneumonia, bronchitis and asthma flare), 18.5\%; fever without a source, 16.2\%; MIS-C, 10.6\%; and gastrointestinal syndrome, $10 \%$. In hospitalised children, the proportions were $28.5 \%, 25.7 \%, 16.5 \%$, $19.1 \%$ and $10.2 \%$, respectively. Risk factors associated with PICU admission were age in months (OR: 1.007; 95\% CI 1.004 to 1.01 ), MIS-C (OR: 14.4, 95\% CI 8.9 to 23.8 ), chronic cardiac disease (OR: 4.8, 95\% CI 1.8 to 13), asthma or recurrent wheezing (OR: 2.5, 95\% CI 1.2 to 5.2) and after excluding MIS-C patients, moderate/severe liver disease (OR: 8.6, 95\% CI 1.6 to 47.6). However, asthmatic children were admitted into the PICU due to MIS-C or pneumonia, not due to asthma flare.

Conclusion: Hospitalised children with COVID-19 usually present as one of five major clinical phenotypes of decreasing severity. Risk factors for PICU include MIS-C, elevation of inflammation biomarkers, asthma, moderate or severe liver disease and cardiac disease.
\end{abstract}

\section{What is Known:}

- All studies suggest that children are less susceptible to serious SARS-CoV-2 infection when compared to adults. Most studies describe symptoms at presentation. However, it remains unclear how these symptoms group together into clinically identifiable syndromes and the severity associated with them.

What is New:

- We have gathered the primary diagnoses into five major syndromes of decreasing severity: MIS-C, bronchopulmonary syndrome, gastrointestinal syndrome, fever without a source and mild syndrome. Classification of the children in one of the syndromes is unique and helps to assess the risk of critical illness and to define the spectrum of the disease instead of just describing symptoms and signs.

Keywords COVID-19 $\cdot$ SARS-CoV-2 $\cdot$ Children $\cdot$ Clinical phenotypes $\cdot$ MIS-C $\cdot$ Severity

\section{Communicated by Nicole Ritz}

Alfredo Tagarro

alfredotagarro@gmail.com

Extended author information available on the last page of the article

Abbreviations
$\begin{array}{ll}\text { COVID-19 } & \text { Coronavirus infectious disease } \\ \text { CRP } & \text { C-reactive protein } \\ \text { FWS } & \text { Fever without source }\end{array}$

\section{Abbreviations}

CRP

Fever without source 


$\begin{array}{ll}\text { HFO } & \begin{array}{l}\text { High-flow oxygen } \\ \text { Interquartile range }\end{array} \\ \text { MIS-C } & \begin{array}{l}\text { Multisystem inflammatory syndrome in } \\ \text { children }\end{array} \\ \text { RT-PCR } & \begin{array}{l}\text { Real-time polymerase chain reaction } \\ \text { OR }\end{array} \\ \text { Odds ratio } \\ \text { PICU } & \text { Paediatric intensive care unit } \\ \text { URTI } & \text { Upper respiratory tract infection }\end{array}$

\section{Introduction}

Children under 18 years of age represented a minority hospitalised COVID-19 cases during the first year of the pandemic [1,2]. Their symptoms are usually milder [3-5]. Symptoms at presentation have been described in some studies [6]; however, it remains unclear how these symptoms group together into clinically identifiable phenotypes.

Only $0.4 \%$ of severe cases are children [7]. Risk factors that lead to severe disease in children have been partly described, and include young age, obesity and underlying comorbidities, lymphopenia and elevation of other inflammatory biomarkers including high C-reactive protein (CRP) [8-10].

The present study aimed to define further the spectrum of COVID-19 in children and the risk factors for hospitalisation and admission in paediatric intensive care units (PICUs) during the first year of the pandemic in Spain.

\section{Methods}

\section{Design}

The Epidemiological Study of Coronavirus in Children (EPICO-AEP) is a multicentre cohort study conducted in Spain to assess the characteristics of children with COVID19. In total, 76 hospitals collected data from the beginning of the epidemic in Spain (March 12th) until March 22nd, 2021. The study was approved by the Ethics Committee of Hospital 12 de Octubre, Madrid (code 20/101), and other participating hospitals. Participants were enrolled after signed or verbal consent from parents/guardians and by the consent of patients older than 12 years.

Eligible participants were children aged from 0 to 18 years who attended in any of the hospitals of the network from the first patient included in March 12th, 2020, to March 22nd, 2021, with a SARS-CoV-2 infection confirmed by real-time polymerase chain reaction (RT-PCR), rapid antigen test or children fulfilling WHO criteria for multisystem inflammatory syndrome in children (MIS-C) [11]. Children hospitalised were enrolled during the whole year. Children attended in the emergency rooms and discharged without admission were recorded only until October 1st, 2020. Of the patients with MIS-C, 31 were described in a prior research report [12]. The protocol included follow-up until discharge.

\section{Laboratory methods}

Respiratory samples for SARS-CoV-2 RT-PCR were obtained from nasopharyngeal swabs and tracheal or bronchial aspirates, when available. Serum samples for SARS$\mathrm{CoV}-2$ serology were analysed in local clinical microbiology laboratories using commercial kits. The remaining haematological, biochemical and microbiological analyses were performed in the laboratories of each centre following routine validated methodology.

\section{Definitions}

Primary diagnoses related to COVID-19 were established according to data supplied by the attending physician. We categorised the diagnoses as the following: MIS-C, pneumonia, bronchitis, bronchiolitis, asthma flare or recurrent wheezing, flu-like syndrome, upper respiratory tract infection (URTI), fever without source (FWS), gastroenteritis, abdominal pain, skin or mucosae problems and asymptomatic. Diagnoses definitions are summarised in Supplementary Table 1 . When more than one simultaneous diagnosis was present, a severity hierarchy was established to define the primary diagnosis, as follows: MIS-C $>$ pneumonia $>$ flu-like $>$ gastroenteritis $>$ bronchitis, bronchiolitis or asthma flare $>$ URTI $>$ fever without a source $>$ abdominal pain $>$ asymptomatic.

Admissions in PICUs did not follow uniform predefined criteria but as per clinical judgement.

For analysis purposes, diagnoses were categorised into five phenotypes: "MIS-C," "bronchopulmonary disease" (including pneumonia, bronchiolitis, bronchitis and asthma flare), "gastrointestinal disease" (including gastroenteritis and abdominal pain), "fever without a source" and "mild disease" (URTI, flu-like syndrome, skin or mucosae problems and asymptomatic patients).

\section{Data management and statistical analyses}

Researchers from each participating hospital collected pseudo-anonymised data using a standardised clinical research form on the electronic data capture system REDCap [13]. Data included main epidemiological, demographic, clinical and laboratory variables.

Continuous variables were categorised according to standard definitions [14]. To dichotomise the continuous 
variables without a standardised categorisation, optimal cut-off points were assessed using generalised additive models implemented in the cutpointr R package [15-17].

We analysed baseline risk factors for hospitalisation and admission into a PICU due to COVID-19 or complications with binary logistic regression. The procedure backwards stepwise (likelihood ratio), as an exploratory test, was performed for those binary variables with a $p$-value $<0.2$ in the univariable analysis. Statistical analyses were performed using SPSS.

\section{Results}

\section{Features of the cohort}

A total of 1200 children were enrolled of whom 666 (55.5\%) were hospitalised. The remaining 534 (45.5\%) children were discharged from the Emergency Departments after evaluation and care (Supplementary Fig. 1). Weekly admissions during the first year of the pandemic are shown in Supplementary Fig. 2.

The median age was 4.7 years (interquartile range [IQR], 9 months to 5.6 years) and 664/1199 (55.4\%) were male. Close contact with a patient with confirmed COVID-19 was confirmed in 644/1182 (54.5\%) participants. Baseline clinical information of the whole cohort is summarised in Tables 1 and 2.
Comorbidities were present in 330 patients $(27.5 \%)$ (Supplementary Table 2). Symptoms at presentation are shown in Fig. 3. The most frequent primary diagnoses were URTI, 290/1200 (24.1\%); fever without a source, 194/1200 (16.1\%); pneumonia, 163/1200 (13.6\%); MIS-C, 127/1200 (10.6\%); flu-like syndrome, 126/1200 (10.5\%); asymptomatic, 115/1200 (9.6\%); gastroenteritis, 86/1200 (7.2\%); bronchitis, 36/1200 (3\%); abdominal pain, 34/1200 (2.8\%); bronchiolitis, 12/1200 (1\%); asthma flare, 11/1200 (0.9\%); and skin or mucosae problems, $6 / 1200(0.5 \%)$.

For a better and easier understanding, we grouped them into five major clinical phenotypes: 538/1200 (44.8\%) presented with mild disease, 222/1200 (18.5\%) bronchopulmonary disease, 192/1200 (16.2\%) fever without a source, 128/1200(10.6\%) MIS-C and 120/1200 (10\%) gastrointestinal disease.

For the 666 hospitalised patients, the frequency of primary diagnosis is presented in Fig. 1. In summary, 189/666 (28.5\%) had mild disease, 171/666 (25.7\%) had bronchopulmonary disease, 127/666 (19.1\%) had MIS-C, 110/666 (16.5\%) had fever without a source and 68/666 (10.2\%) had gastrointestinal disease.

The overlapping of diagnoses was not relevant: only $6 \%$ of children with respiratory disease had also gastrointestinal disease, and $20 \%$ of children with MIS-C had an X-ray compatible with pneumonia.

The patients with mild disease were admitted for different reasons, including significant prior serious comorbidity

Table 1 Summary characteristics of the total cohort globally and categorised by hospitalisation

\begin{tabular}{|c|c|c|c|c|c|c|c|c|c|}
\hline \multirow[t]{2}{*}{ Feature } & \multicolumn{2}{|l|}{ Total } & \multicolumn{2}{|c|}{ Not hospitalised } & \multicolumn{2}{|c|}{ Hospitalised not PICU } & \multicolumn{2}{|l|}{ PICU } & \multirow[t]{2}{*}{$p$-value } \\
\hline & $N=1200$ & $\%$ of 1200 & $n=534$ & $\%$ of feature & $n=543$ & $\%$ of feature & $n=123$ & $\%$ of feature & \\
\hline Phenotypes & & & & & & & & & $<0.001$ \\
\hline Mild & 537 & 44.8 & 347 & 64.6 & 178 & 33.1 & 12 & 2.2 & \\
\hline Bronchopulmonary & 222 & 18.5 & 51 & 23.0 & 143 & 64.4 & 28 & 12.6 & \\
\hline Fever without a source & 194 & 16.2 & 84 & 43.3 & 108 & 55.7 & 2 & 1.0 & \\
\hline $\begin{array}{l}\text { MIS-C (multisystem } \\
\text { inflammatory syndrome) }\end{array}$ & 127 & 10.6 & 0 & 0.0 & 51 & 40.2 & 76 & 59.8 & \\
\hline Gastrointestinal & 120 & 10.0 & 52 & 43.3 & 63 & 52.5 & 5 & 4.2 & \\
\hline Sex & & & & & & & & & 0.05 \\
\hline Male & 665 & 55.4 & 280 & 42.1 & 306 & 46.0 & 79 & 11.9 & \\
\hline Close contact with COVID-19 & 644 & 53.7 & 309 & 48.0 & 280 & 43.5 & 55 & 8.5 & 0.013 \\
\hline Codetection & 112 & 9.3 & 15 & 13.4 & 72 & 64.3 & 25 & 22.3 & 0.044 \\
\hline Virus-virus & 33 & 2.8 & 8 & 24.2 & 16 & 48.5 & 9 & 27.3 & \\
\hline Virus-bacteria & 78 & 6.5 & 7 & 9.0 & 55 & 70.5 & 16 & 20.5 & \\
\hline Respiratory support & & & & & & & & & $<0.001$ \\
\hline Oxygen & 182 & 15.2 & 6 & 3.3 & 89 & 48.9 & 87 & 47.8 & \\
\hline High-flow therapy & 42 & 3.5 & & 0.0 & 8 & 19.0 & 34 & 81.0 & \\
\hline Mechanical ventilation & 32 & 2.7 & & 0.0 & & 0.0 & 32 & 100.0 & \\
\hline Complications & 210 & & 4 & 1.9 & 109 & 51.9 & 97 & 46.2 & $<0.001$ \\
\hline
\end{tabular}


Table 2 Summary characteristics of the total cohort globally and categorised by hospitalisation (continuous variables)

\begin{tabular}{|c|c|c|c|c|c|}
\hline & $\begin{array}{l}\text { Total } \\
N=1200\end{array}$ & $\begin{array}{l}\text { Not hospitalised } \\
n=534\end{array}$ & $\begin{array}{l}\text { Hospitalised not PICU } \\
n=543\end{array}$ & $\begin{array}{l}\text { PICU } \\
n=123\end{array}$ & $p$-value \\
\hline \multirow[t]{2}{*}{$\begin{array}{l}\text { Age (months), } \\
\text { Median [IQR] }\end{array}$} & $58[9-136]$ & $63[13-130]$ & 36 [2-129.75] & $\begin{array}{l}120 \text { [61-157] (excluding MIS- } \\
\text { C): } 101[5-165]\end{array}$ & $<0.001$ \\
\hline & $n=1156$ & $n=497$ & $n=536$ & $n=123$ & \\
\hline \multirow{2}{*}{$\begin{array}{l}\text { Weight percentile, } \\
\text { Median [IQR] }\end{array}$} & $50[21-81]$ & $53[28-88]$ & $41[16.25-75]$ & $53.5[24-78]$ & $<0.001$ \\
\hline & $n=979$ & $n=401$ & $n=476$ & $n=102$ & \\
\hline \multirow{2}{*}{$\begin{array}{l}\text { Fever days } \\
\text { Median [IQR] }\end{array}$} & $3[2-6]$ & $3[2-4]$ & $4[2-7]$ & $7[5-9]$ & $<0.001$ \\
\hline & $n=777$ & $n=275$ & $n=400$ & $n=102$ & \\
\hline \multirow{2}{*}{$\begin{array}{l}\text { Heart frequency } \\
\text { Median [IQR] }\end{array}$} & $124[100-145]$ & $110.5[91-137]$ & $130[105-150]$ & $126[110-144]$ & $<0.001$ \\
\hline & $n=874$ & $n=268$ & $n=487$ & $n=119$ & \\
\hline \multirow{2}{*}{$\begin{array}{l}\text { Respiratory frequency, } \\
\text { Median [IQR] }\end{array}$} & $30[22-40]$ & $26[20-35]$ & $31[24-41]$ & $30[22-44]$ & 0.004 \\
\hline & $n=450$ & $n=89$ & $n=277$ & $n=84$ & \\
\hline \multirow{2}{*}{$\begin{array}{l}\text { Oxygen saturation (\%), } \\
\text { Median [IQR] }\end{array}$} & 98 [97-99] & 98 [97-99] & 98 [97-99] & 98 [95-99] & 0.073 \\
\hline & $n=872$ & $n=273$ & $n=482$ & $n=117$ & \\
\hline \multirow{2}{*}{$\begin{array}{l}\text { Systolic blood pressure } \\
\text { Median [IQR] }\end{array}$} & $102[91-114]$ & 110 [96-119] & $102[92-111]$ & $97[85-115]$ & $<0.001$ \\
\hline & $n=517$ & $n=87$ & $n=319$ & $n=111$ & \\
\hline \multirow{2}{*}{$\begin{array}{l}\text { Diastolic blood pressure } \\
\text { Median [IQR] }\end{array}$} & 60 [52-69] & $63[56-70]$ & 60 [52-69] & 55 [47-67] & 0.001 \\
\hline & $n=517$ & $n=87$ & $n=319$ & $n=111$ & \\
\hline \multirow{2}{*}{$\begin{array}{l}\text { Haemoglobin }(\mathrm{g} / \mathrm{dL}) \text {, } \\
\text { Median [IQR] }\end{array}$} & $12[10-13]$ & $12.5[11-13]$ & $12[10-14]$ & $11[9-12]$ & 0.123 \\
\hline & $n=86$ & $n=16$ & $n=55$ & $n=15$ & \\
\hline \multirow{2}{*}{$\begin{array}{l}\text { Leucocytes }\left(\mathrm{mm}^{3}\right) \text {, } \\
\text { Median }[\mathrm{IQR}]\end{array}$} & $7900[5120-11,697.5]$ & 7300 [50750-9842] & 7870 [5135-11480] & 9600 [5205-15795] & 0.005 \\
\hline & $n=704$ & $n=118$ & $n=465$ & $n=121$ & \\
\hline \multirow{2}{*}{$\begin{array}{l}\text { Lymphocytes }\left(\mathrm{mm}^{3}\right) \text {, } \\
\text { Median [IQR] }\end{array}$} & 1960 [992.5-3565] & $2450[1340-4000]$ & $2150[1115-3725]$ & 800 [415-1852] & $<0.001$ \\
\hline & $n=700$ & $n=115$ & $n=465$ & $n=120$ & \\
\hline \multirow{2}{*}{$\begin{array}{l}\text { Neutrophils }\left(\mathbf{m m}^{3}\right) \text {, } \\
\text { Median [IQR] }\end{array}$} & $3640[1800-7400]$ & $3100[1600-4900]$ & 3451 [1747.5-7017.5] & $6995[2775-12,847.5]$ & $<0.001$ \\
\hline & $n=701$ & $n=115$ & $n=466$ & $n=120$ & \\
\hline \multirow{2}{*}{$\begin{array}{l}\text { Platelets }\left(\mathbf{m m}^{3}\right) \text {, } \\
\text { Median [IQR] }\end{array}$} & 255,500 [165000-379500] & 267,000 [202750-363500] & 270,000 [182000-389000] & $180,000[103000-311000]$ & $<0.001$ \\
\hline & $n=730$ & $n=128$ & $n=479$ & $n=123$ & \\
\hline \multirow{2}{*}{$\begin{array}{l}\text { AST (U/L), } \\
\text { Median [IQR] }\end{array}$} & 36 [25-55] & $31[22-48.5]$ & 34 [25-50] & 49 [32-82] & $<0.001$ \\
\hline & $n=554$ & $n=88$ & $n=355$ & $n=111$ & \\
\hline \multirow{2}{*}{$\begin{array}{l}\text { ALT (U/L), } \\
\text { Median [IQR] }\end{array}$} & $24[15-45]$ & $20[15-29.5]$ & 22 [15-39] & $25[43.5-87]$ & $<0.001$ \\
\hline & $n=625$ & $n=105$ & $n=403$ & $n=117$ & \\
\hline \multirow{2}{*}{$\begin{array}{l}\text { C-reactive protein }(\mathrm{mg} / \mathrm{L}) \text {, } \\
\text { Median [IQR] }\end{array}$} & $43[5-152.75]$ & $3.5[1-11.25]$ & $18[4.5-112]$ & $195[120.5-246.5]$ & $<0.001$ \\
\hline & $n=180$ & $n=26$ & $n=109$ & $n=45$ & \\
\hline \multirow{2}{*}{$\begin{array}{l}\text { Procalcitonin }(\mathrm{ng} / \mathrm{mL}), \\
\text { Median [IQR] }\end{array}$} & $9.5[5-32.5]$ & $5[5-5]$ & $6[4.25-28.25]$ & 16 [11-99] & 0.246 \\
\hline & $n=16$ & $n=1$ & $n=8$ & $n=7$ & \\
\hline \multirow{2}{*}{$\begin{array}{l}\text { Serum sodium }(\mathrm{mEq} / \mathrm{L}) \text {, } \\
\text { Median [IQR] }\end{array}$} & 137 [135-139] & $138[136.5-140]$ & 137 [135-139] & 135 [133-139] & $<0.001$ \\
\hline & $n=619$ & $n=97$ & $n=406$ & $n=116$ & \\
\hline \multirow{2}{*}{$\begin{array}{l}\text { Lactate dehydrogenase } \\
(\mathrm{U} / \mathrm{L}), \\
\text { Median [IQR] }\end{array}$} & $321[250-417]$ & $248[203-312.5]$ & $326.5[258-416.25]$ & $368[287.25-507.5]$ & $<0.001$ \\
\hline & $n=455$ & $n=65$ & $n=284$ & $n=106$ & \\
\hline \multirow{2}{*}{$\begin{array}{l}\text { D-dimer }(\mu \mathrm{g} / \mathrm{L}) \text {, } \\
\text { Median [IQR] }\end{array}$} & 1150 [448-3066.5] & $350[187-810]$ & 926 [427-1965] & 3078 [1631.5-5985] & $<0.001$ \\
\hline & $n=361$ & $n=29$ & $n=235$ & $n=97$ & \\
\hline \multirow{2}{*}{$\begin{array}{l}\text { IL-6 }(\mathrm{pg} / \mathrm{mL}) \\
\text { Median [IQR] }\end{array}$} & $99.5[12.25-1328.75]$ & & $12[6-65]$ & $263.5[64.5-611.5]$ & $<0.001$ \\
\hline & $n=76$ & - & $n=34$ & $n=42$ & \\
\hline Ferritin (ng/mL), & $282[97-680]$ & $77[41.5-279]$ & $208.5[78.5-522.75]$ & 552 [282.75-1312.5] & $<0.001$ \\
\hline Median [IQR] & $n=299$ & $n=21$ & $n=196$ & $n=82$ & \\
\hline Urea (mg/dL), & $24[17-32]$ & $24.5[16-32]$ & $23[17-30]$ & 31 [21.5-49.5] & $<0.001$ \\
\hline Median [IQR] & $n=490$ & $n=66$ & $n=327$ & $n=97$ & \\
\hline NT-proBNP (pg/mL), & 7994 [3676-17974] & & $4650.5[1653.25-9066.5]$ & 10,324 [4051-20404] & 0.011 \\
\hline Median [IQR] & $n=67$ & - & $n=24$ & $n=43$ & \\
\hline Troponin I (ng/mL), & 320 [51-691] & - & $78.5[30-\mathrm{xx}]$ & 525 [72-702] & 0.236 \\
\hline Median [IQR] & $n=13$ & & $n=2$ & $n=11$ & \\
\hline
\end{tabular}

$P I C U$, paediatric intensive care unit; $I Q R$, interquartile range; $A S T$, aspartate aminotransferase; $A L T$, alanine aminotransferase; $I L-6$, interleukin 6; NT-proBNP, N-terminal pro-B type natriuretic peptide 

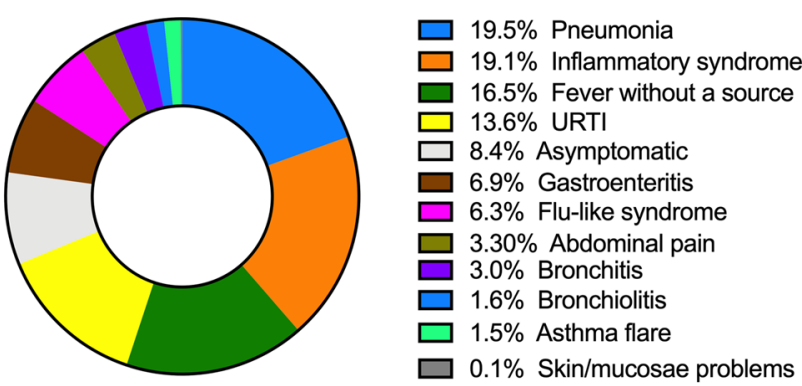

Fig. 1 Primary diagnoses of the 666 patients admitted with COVID19

(18.8\%), current concomitant autoimmune or thrombotic comorbidity (12.8\%), current concomitant comorbidities not related with COVID-19 (11.3\%), bacterial coinfections $(8.5 \%)$, isolation $(4.3 \%)$, other $(3.2 \%)$ and unspecified reasons $(40.9 \%$ ) (see Supplementary Table 3).

A total of 206/666 (30.9\%) hospitalised patients had complications. The most frequent complications were cardiological 75/666 (11.3\%) and 59/666 (8.9\%) shock. Cardiological complications included myocardial dysfunction $7.2 \%$; valve dysfunction $2.6 \%$; arrhythmia $2 \%$; coronary abnormalities $1.8 \%$; and aneurysms $0.5 \%$. Other complications are outlined in Supplementary Table 4.

Coinfections were found in 97/666 (14.5\%) patients, most often bacterial-viral infections $(71 / 666 ; 10.6 \%)$.

\section{Patients admitted to the PICU}

A total of 123/666 (18.4\%) hospitalised patients were admitted to a PICU, for a median of 5 (IQR 3) to 8 days (Table 1). The most frequent diagnoses were MIS-C 76/123 (61.8\%) and pneumonia $27 / 123(22 \%)$.

Nine (1.3\% of hospitalised) patients died. Five of them had coinfections ( 3 bacterial due to Enterococcus faecalis, Enterococcus faecium and Clostridium difficile), and two viral (Parainfluenzae and type 1 herpes virus). All except one had serious comorbidities, which were malignancies $(n=3)$, autoimmune chronic pulmonary disease, dilated myocardiopathy, STAT-3 immunodeficiency, severe congenital immunodeficiency and bronchopulmonary dysplasia. Three of them had haematopoietic stem cell transplantation. One patient without serious comorbidities had moderate overweight (body mass index, 24).

Four children needed extracorporeal membrane oxygenation support (ECMO), two of them died. A total of 57/123 $(46.3 \%)$ children required inotropic support.

The risk of needing PICU admission was different across major clinical phenotypes. In the univariable analysis, only MIS-C had an increased risk of PICU (odds ratio [OR]: 32.5, 95\% CI 20.5 to 51.5). Bronchopulmonary disease had an OR of 1.3 (95\% CI 0.8 to 21.1 ), and the rest were protective:
FWS (OR: 0.07, 95\% CI 0.01 to 0.1), gastrointestinal disease (OR: $0.3,95 \%$ CI 0.1 to 0.8 ) and mild disease (OR: $0.1,95 \%$ CI 0.06 to 0.2 ) (Fig. 2).

In the univariable model, male sex (OR: 1.5, 95\% CI 1.02 to 2.2), not having an identified close contact (OR: 1.6, 95\% CI 1.1 to 2.5) and some specific comorbidities as chronic cardiac disease (OR: 2.5, 95\% CI 1.07 to 5.9), asthma or recurrent wheezing (OR: 2.1, 95\% CI 1.2 to 3.9) and moderate/severe liver disease (OR: 5.3, 95\% CI 1.2 to 22.7) were predictors for PICU admission.

In the multivariable model, baseline risk factors associated with PICU admission were age in months (OR: 1.007; 95\% CI 1.004 to 1.01 ), MIS-C (OR: $14.4,95 \%$ CI 8.9 to 23.8), chronic cardiac disease (OR: $4.8,95 \%$ CI 1.8 to 13 ) and asthma or recurrent wheezing (OR: $2.5,95 \%$ CI 1.2 to 5.2). However, out of 18 children with pre-existing asthma or recurrent wheezing, none of them was admitted with asthma flare, but ten were admitted with MIS-C and eight with pneumonia. Excluding MIS-C, only age in months (OR: 1.005 ; $95 \%$ CI 1.001 to 1.009 ) and moderate/severe liver disease (OR: 8.6, 95\% CI 1.6 to 47.6) remained significant.

Among those patients with blood tests performed (see Table 2), abnormalities were also associated with PICU admission; specifically leucocytosis $>15,000 / \mathrm{mm}^{3}$ (OR: 2.4, $95 \%$ CI 1.5 to 3.9), neutrophilia $>10,000 / \mathrm{mm}^{3}$ (OR: 4.3 , $95 \%$ CI 2.8 to 6.8 ), lymphopenia $<1000 / \mathrm{mm}^{3}$ (OR: $5.6,95 \%$ CI 3.6 to 8.6 ), thrombopenia $<150,000 / \mathrm{mm}^{3}$ (OR: $4.9,95 \%$ CI 3.2 to 7.5 ), CRP $>20 \mathrm{mg} / \mathrm{L}$ (OR: $18.9,95 \%$ CI 5.5 to 64 ), GPT $>37$ U/L (OR: $4.2,95 \%$ CI 2.8 to 6.5 ), $\mathrm{LDH}>500 \mathrm{U} / \mathrm{L}$ (OR: $2.2,95 \%$ CI 1.3 to 3.8 ), hyponatremia $<135 \mathrm{mmol} / \mathrm{L}$ (OR: 3.4, 95\% CI 2.2 to 5.2), D-dimer $>500 \mathrm{ng} / \mathrm{mL}$ (OR: 4.4, $95 \%$ CI 2.1 to 8.9 ), IL-6>8.5 pg/mL (OR: $32.2,95 \%$ CI 3.9 to 263 ), ferritin $>400 \mathrm{mg} / \mathrm{dL}$ (OR: $3.9,95 \%$ CI 2.2 to 6.7 ).

\section{MIS-C patients}

A total of 127 (19.1\% of hospitalised) children were diagnosed with MIS-C. The median age was 9.2 years (IQR 5.2 to 12.5$)$. Of them, 35 (27.6\%) fulfilled the criteria for Kawasaki disease, and 76/127 (59.8\%) needed admission to a PICU.

A total of 54 children (42.5\%) had positive SARS-CoV-2 RT-PCR in respiratory samples (nasopharyngeal swab or bronchial aspirate); IgM was positive in 32/99 (32\%) and IgG in 96/105 tested (91\%). All patients who were IgM positive were also IgG positive. Blood tests found in MIS-C revealed high-level inflammation and target-organ damage (Supplementary Table 5).

Cardiological complications $(71 / 127,56 \%)$ consisted of myocardial dysfunction 48/127 (37\%), valvular dysfunction 17/127 (13\%), pericardial effusion 12/127 (9.4\%), arrhythmias $12 / 127(9.4 \%)$ and coronary abnormalities $12 / 127$ 
Fig. 2 Odds ratio and 95\% confidence interval of PICU admission across major phenotypes. Horizontal axis is displayed as $\log (10)$ scale. FWF, fever without a source; G-I, gastrointestinal disease; MIS-C, multiinflammatory syndrome

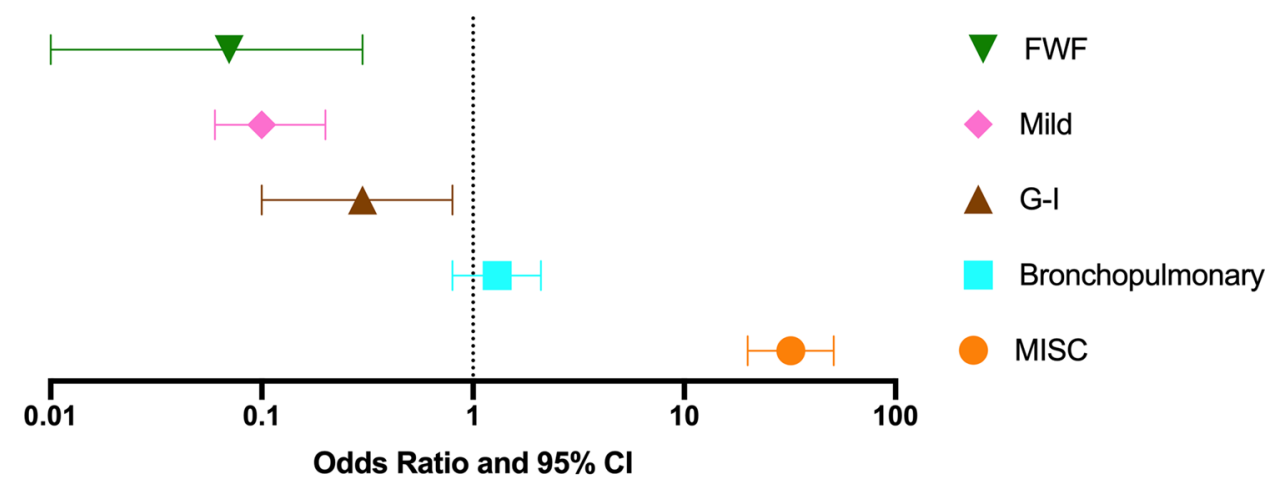

(9.4\%), of which $3 / 127$ (2.3\%) were aneurysms, and one of them a giant aneurysm in anterior descending artery $(Z$-score +9$)$. Other complications included renal failure $17 / 127$ (13.3\%), need of mechanical ventilation $16 / 127$ (12.5\%) and need of oxygen 58/127 (45.7\%).

Three patients died: one patient with acute leukaemia and bone marrow transplant, one with overweight and one with malignant neoplasm.

Specific treatment was provided as follows: steroids only $22 / 126$ (17.3\%), intravenous immunoglobulin only 18/126 (14.2\%), both 79/126 (62.2\%) and none 7/126 (5.5\%). Steroids used were mostly intravenous metil-prednisolone (119/126, 95\%).

Median time of PICU admission was 5 days [3 to 7], and median time of admission was 9 days [6 to 12].

In the multivariable model, baseline features that in the model were associated with MIS-C were age in months (OR: 1.01, CI 95\%: 1.007 to 1.01), male gender (OR: 1.7, CI 95\%: 1.1 to 2.6 ) and immunosuppressive medication (OR: 6.4, $95 \%$ CI 2.2 to 18.5 ).

\section{Discussion}

In this study, we have identified the spectrum of COVID19 in children attended in Spanish hospitals during the first year of pandemic. Initial features of COVID-19 are very unspecific, and patients may show a very wide spectrum of sign and symptoms, as shown in Fig. 3. We have identified twelve frequent diagnoses that can be grouped into five major clinical phenotypes for a more practical approach: MIS-C, bronchopulmonary disease, gastrointestinal disease, fever without a source (FWS) and mild disease. This classification better defines COVID-19 in children than previous definitions and can guide severity assessment.

We identified similar risk factors for critical disease as other studies $[8,18,19]$. We added some new factors, especially specific comorbidities. Interestingly, immunosuppression and neoplasia were not risk factors for PICU admission, although most deceased patients had serious immunosuppression or cancer. Most deceased patients were patients with severe comorbidities, and half of them had coinfections.

Age, asthma or recurrent wheezing and heart diseases are risk factors for PICU admission. Liver disease was in the limit of significance. Interestingly, asthmatic patients were not admitted to the PICU due to asthma flare, but due to pneumonia or MIS-C. These risk factors seem to influence predominantly patients with MIS-C, because after excluding patients with MIS-C of the analysis, only age and chronic liver disease remained as risk factors for PICU. Additionally, immunosuppressive treatments were risk factors for MIS-C. This may be considered for stepwise immunisation strategies in children, so those with significant pre-existing comorbidities get immunised first.

Other risk factors as IL-6, CRP, D-dimer and cytopaenia suggest immune dysregulation and severe inflammation in critical patients. CD4 and natural killer T-cell cytopaenia due to immune dysregulation have been described previously [20].

Immune dysregulation may also be involved in manifestations that are not clearly related to COVID-19 but have been found in this and other cohorts, such as diabetic debut, haemolytic anaemia or appendicitis. A significant increase in diabetic ketoacidosis in children was found during the COVID-19 pandemic [21]. A clinical picture consistent with appendicitis in children has been reported, as well as ileitis [22,23]. In this study, some patients with appendicitis, diabetic debut and ileitis were also identified concomitantly or soon after SARS-CoV-2 infection.

Immune dysregulation is also involved in MIS-C. Some features of MIS-C, such as shock or cardiac disease, may be responsible for laboratory abnormalities such as high ALT or creatinine (Supplementary Table 5). However, specific mechanisms for kidney injury secondary to COVID19 have been previously proposed [24].

The national seroprevalence study ENE-COVID [2] suggests that in December, 400,000 children were seropositive in Spain. Considering that our study included $10 \%$ of the 800 private and public hospitals of Spain, including 
Fig. 3 Signs and symptoms at presentation of the 1200 enrolled patients. Those present in $<5 \%$ of patients are not displayed

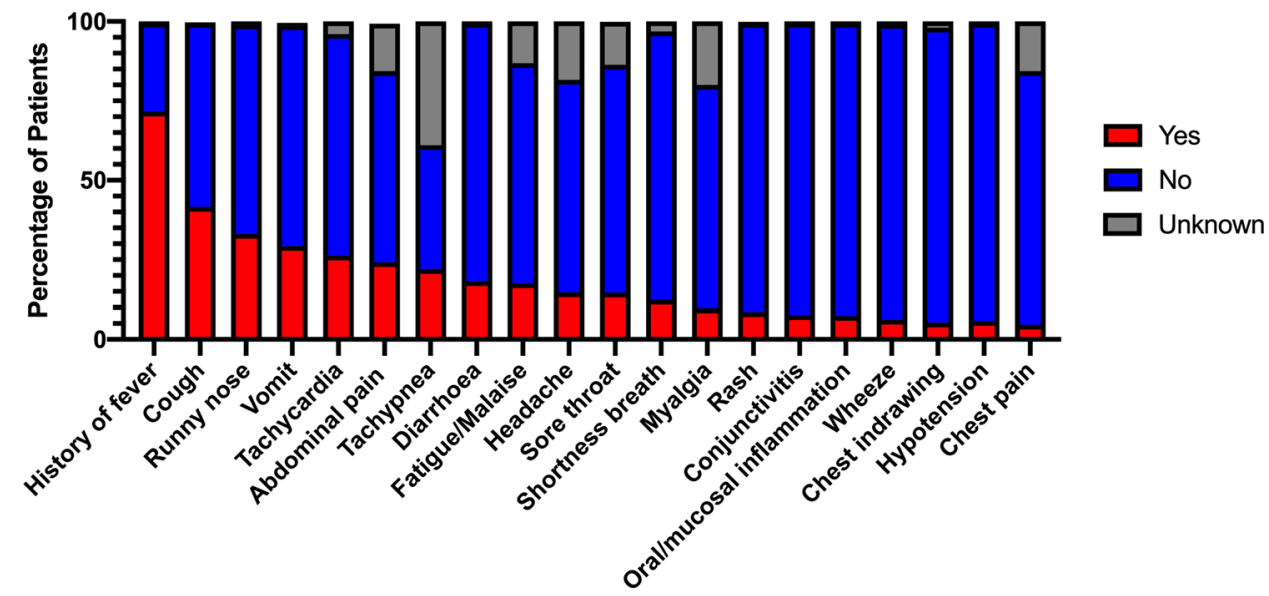

most tertiary public hospitals, likely less than $1 \%$ of children with COVID-19 needed hospitalisation; and less than $0.05 \%$ needed intensive care.

This study included children attended in different hospitals. There is a risk of selection, case identification and reporting bias for hospitalisation and for PICU admission. Access to SARS-CoV-2 testing was not consistent during the enrolment, especially during the first wave. The diversity and broadness of the study are strengths, as they provide insight into the disease in a major clinical part of Spain through a prospective collection of data.

Although viral-bacterial coinfection was found in a significant proportion of hospitalised children, a full workup for coinfections was not done uniformly, and thus the role of coinfections is not completely clear. The study included few neonates because most neonates with COVID-19 in Spain were included in a different neonatal registry.

The ethnic origin was not recorded, so we cannot compare our study with other studies suggesting worse outcome in minorities. The categorisation and interpretation of this variable tend to be simplistic--for instance, Black versus others or Caucasians versus others, and the minority factor is often linked to economical and sociodemographic characteristics, which we did not collect $[25,26]$.

We believe that this classification is unique and helps to define the spectrum of the disease instead of just describing symptoms and signs. Understanding different clinical manifestations, and the heterogeneity of infection and postinfection manifestations, may help in diagnostic strategies.

\section{Conclusions}

The infrequent COVID-19 that requires hospitalisation in children presents as any of five major clinical phenotypes of decreasing severity: MIS-C, bronchopulmonary disease, gastrointestinal disease, mild disease and fever without a source. Risk factors for PICU include MIS-C, inflammation biomarkers and specific comorbidities as asthma, moderate or severe liver disease, and cardiac disease.

Supplementary information The online version contains supplementary material available at https://doi.org/10.1007/s00431-021-04306-6.

Acknowledgements We thank all the patients and families for their participation in the study, and the laboratory staff and clinical staff members who cared for them. Thanks to Kenneth McCreath (Universidad Europea de Madrid) for the style and English revision. EPICO-AEP Working Group: Francisco José Sanz, María Isabel Iglesias-Bouzas, Jose Antonio Alonso Cadenas, Blanca Herrero (Hospital Infantil Universitario Niño Jesús), Teresa del Rosal, Ana Méndez-Echevarría, Talía Sainz, Clara Udaondo, Fernando Baquero, Cristina Calvo, Carlos Grasa, Paula R Molino, María José Mellado, María Ceano, Victor Galán, Marta Melgosa, Paula Garcia Sanchez, Sonsoles San Roman (Hospital Universitario La Paz), Alicia Hernanz Lobo, Mar Santos, Marisa Navarro, Elena Rincón, David Aguilera, Begoña Santiago, Jorge Huerta, Eduardo Bardón, Jorge Lorente (Hospital Universitario Gregorio Marañón), Pablo Rojo, Daniel Blázquez, Luis Prieto, Elisa Fernández-Cooke, David Torres-Fernández, Ángela Manzanares, Jaime Carrasco, Cristina Epalza, Jesús Contreras, Sara Domínguez, Sara Villanueva, Arantxa Gonzalez (Hospital Universitario 12 de Octubre), Cinta Moraleda, Alfredo Tagarro, Elena Cobos, Álvaro Ballesteros, Sara DomínguezRodriguez (Instituto de Investigación 12 de Octubre), Gemma Pons, Silvia Simó, Miguel Lanaspa, Victoria Fumadó, Rosa María Pino, (Hospital Sant Joan de Déu), María Espiau, Jacques G. Rivière, Pere Soler-Palacín, Antonio Soriano Arandes, Natalia Mendoza (Hospital Universitari Vall d'Hebron), Mercedes Herranz, María Urretavizcaya Martínez (Complejo Hospitalario de Navarra), Fernando Cabañas, Fátima Ara, Marta Baragaño (Hospital Universitario Quirónsalud Madrid), Rut del Valle, Ana González-de-Zárate, Mónica Pacheco, María Luisa Herreros, Julia Yebra, Beatriz Pérez-Seoane, María Fernández, Teresa Raga, María de la Serna, Ane Plazaola, Juan Miguel Mesa, Rosa Batista, Ana Barrios, Ignacio Navarro, Jana Rizo, Teresa Reinoso, Alfonso Cañete (Hospital Universitario Infanta Sofía), María Dolores Martín, Elena Sáez, Olga Nerea Coya, Fernando Cava (BR Salud), Enrique Otheo, Juan Carlos Galán, José Luis Vázquez, Carmen Vázquez, Victor Quintero (Hospital Universitario Ramón y Cajal), Lola Falcón, Olaf Neth, Peter Olbrich, Walter Goicoechea, Cati Márquez, Marisol Camacho, Inés Marín Cruz (Hospital Universitario Virgen del Rocío), Laura Martín (Hospital Universitario Regional de Málaga), Lucía Figueroa (Hospital de Villalba), María Llorente (Hospital Universitario del Sureste), María Penin, Claudia García, 
María García, Teresa Alvaredo (Hospital Universitario Príncipe de Asturias), M $^{a}$ Inmaculada Olmedo, Agustín López, María Jose Pérez (Hospital Universitario Puerta de Hierro), Elvira Cobo (Hospital Fundación Alcorcón), Mariann Tovizi (Hospital del Tajo), Pilar Galán (Hospital Fundación Fuenlabrada), Beatriz Soto, Sara Guillén (Hospital de Getafe), Adriana Navas (Hospital Universitario Infanta Leonor) M. Luz García (Hospital de Leganés), Sara Pérez (Hospital de Torrejón), Amanda Bermejo, Pablo Mendoza (Hospital de Móstoles), Gema Sabrido (Hospital Rey Juan Carlos), María José Hernández (Hospital Central de la Defensa), Ana Belén Jiménez (Fundación Jiménez Díaz), Arantxa Berzosa, José Tomás Ramos, Marta Illán (Hospital Clínico San Carlos), Ana López, Nerea Gallego (Hospital Universitari Son Espases), Beatriz Ruiz (Hospital Universitario Reina Sofía), Santiago Alfayate, Ana Menasalvas, Eloísa Cervantes (Hospital Clínico Universitario Virgen de la Arrixaca), María Méndez (Institut d'Investigació en Ciències de la Salut Germans Trias i Pujol), Ángela Hurtado (Instituto Hispalense de Pediatría), Cristina García, Inés Amich, Yolanda Ruiz (Hospital San Pedro), Manuel Oltra, Álvaro Villarroya-Villalba, Adela Cañete, Bienvenida Argiles (Hospital Universitari i Politècnic La Fe), Angustias Ocaña (Hospital La Moraleja), Isabel Romero, María Fernanda Guzmán (Hospitales Madrid), M.J. Pascual (Hospital Nisa), María SánchezCódez (Hospital Universitario Puerta del Mar), Elena Montesinos (Consorci Hospital General Universitari de València), Julia Jensen, María Rodríguez (Hospital Universitario Infanta Cristina), Gloria Caro (Hospital Universitario Infanta Elena), Neus Rius, Alba Gómez (Hospital Universitari Sant Joan de Reus), Rafael Bretón (Hospital Clínico Universitario de Valencia), Margarita Rodríguez, Julio Romero, Juan Francisco Pascual Gazquez (Hospital Universitario Virgen de las Nieves), Ana Campos (Hospital Universitario Sanitas La Zarzuela), Mercedes García (Hospital de Mérida), Rosa María Velasco (Complejo Hospitalario de Toledo), Zulema Lobato (Althaia, Xarxa Assistencial Universitària de Manresa), Fernando Centeno, Elena Pérez, Alfredo Cano (Hospital Universitario Río Hortega), Paula Vidal (Hospital Clínico Universitario Lozano Blesa), Corsino Rey, Ana Vivanco, Maruchi Alonso (Hospital Universitario Central de Asturias), Pedro Alcalá, Javier González de Dios, Laura Ureña Horno (Hospital General Universitario de Alicante), Eduard Solé, Laura Minguell (Hospital Universitari Arnau de Vilanova), Itziar Astigarraga, Olatz Villate, Susana García Obregón (Hospital Universitario de Cruces), $\mathrm{M}^{\mathrm{a}}$ Ángeles Vázquez, Miguel Sánchez, Leticia Martínez Campos (Hospital Universitario Torrecárdenas), Elena Díaz (Hospital Virgen de la Luz), Eduardo Consuegra, Susana Riesco, Almudena González, Maika Mendoza (Hospital Universitario de Salamanca), María Cabanillas (Complejo Asistencial Universitario de Palencia), Yeray Novoa-Medina, Elena Colino-Gil, Ana Reyes-Domínguez, Luis Peña-Quintana (Hospital Universitario Materno Infantil de las Palmas), Elisa Garrote, Maite Goicoechea, Ainhoa Gondra Sangroniz (Hospital Universitario de Basurto), Irene Centelles (Hospital General Universitari de Castelló), Santiago Lapeña, Sara Gutiérrez, Soraya Gutiérrez (Complejo Asistencial Universitario de León), Amparo Cavalle (PIUS Hospital de Valls), José María Olmos (Hospital Mare de Déu dels Lliris), Alejandro Cobo, Sara Díaz, Cristina Martinez Faci, Macarena Gonzalez Cruz, Beatriz Castro (Hospital Universitario de Canarias), Beatriz Jiménez, Cristina Alvarez Alvarez (Hospital Universitario Marqués de Valdecilla), Raúl González (Hospital Sant Joan d'Alacant), Miguel Lafuente, Matilde Bustillo (Hospital Infantil de Zaragoza), Natividad Pons, Julia Morata (Hospital Lluís Alcanyis), Elsa Segura (Hospital Universitario Son Llatzer de Palma de Mallorca), María Bernardino (Universidad Europea de Madrid), Marta Pareja León (Complejo Hospitalario Universitario de Albacete), Ana Domingo Ruiz (Hospital de Manacor), Eider Oñate, Nagore Garcia de Andoin Baran (Hospital Universitario Donostia), Nerea DomínguezPinilla (Hospital Virgen de la Salud), María Teresa Coll Sibina (Hospital General de Granollers), María Jesús García García (Hospital Universitario de Cáceres), Marta Osuna (Hospital HM Montepríncipe),
Raquel Portugal (Hospital Universitario de Burgos), Leonor García Maset (Hospital de Sagunto), Belén Sevilla (Hospital Universitario San Cecilio Granada), Noelia Berciano Jiménez (Hospital Virgen de la Macarena, Sevilla).

Authors' contributions AT and CM conceptualised and designed the study. AT performed the statistical analysis. AT, CM, CG, AS and SV drafted the manuscript. All co-authors participated in the collection of data. All co-authors participated and were involved in the critical review of the final manuscript.

Funding The study was funded by: Project PI20/00095, from the Instituto de Salud Carlos III (Ministry of Economy, Industry and Competitiveness) and cofounded by the European Regional Development Fund; and by SERMAS-Fundación para la Investigación Biomédica del Hospital 12 de Octubre, Elena Cobos is supported by a specific Research Project of the Spanish Society of Paediatrics (Asociación Española de Pediatría); Grant Covid-19 EPICO-AEP 2020, Carlos Grasa is funded by the Spanish Ministry of Science and Innovation-Instituto de Salud Carlos III and Fondos FEDER (Contrato Río Hortega CM19/00015), Serena Villaverde is funded by the Spanish Ministry of Science and Innovation-Instituto de Salud Carlos III and Fondos FEDER (Contrato Río Hortega CM20/00173), Juan Miguel Mesa is funded by SERMAS-Fundación para la Investigación Biomédica del Hospital Infanta Sofía y del Henares, María Bernardino is funded by the Becas Cantera Santander-Fundación Universidad Europea de Madrid.

Availability of data and material Available on reasonable request.

\section{Declarations}

Ethics approval The study was approved by the Ethics Committee of Hospital 12 de Octubre, Madrid (code 20/101), and other participating hospitals.

Consent to participate Participants were enrolled after signed or verbal consent from parents/guardians and by the consent of patients older than 12 years.

Consent for publication Not applicable.

Conflict of interest The authors declare no competing interests.

\section{References}

1. Qiu H, Wu J, Hong L, Luo Y, Song Q, Chen D (2020) Clinical and epidemiological features of 36 children with coronavirus disease 2019 (COVID-19) in Zhejiang, China: an observational cohort study. Lancet Infect Dis [Internet] 20(6):689-96. Available from: https://doi.org/10.1016/S1473-3099(20)30198-5

2. Instituto de Salud Carlos III (2020) Estudio ENE-COVID: cuarta ronda estudio nacional de sero-epidemiología de la infección por SARS-COV-2 en España. December 15th

3. Gudbjartsson DF, Helgason A, Jonsson H, Magnusson OT, Melsted P, Norddahl GL et al (2020) Spread of SARS-CoV-2 in the Icelandic population. N Engl J Med 382(24):2302-2315

4. Lavezzo E, Franchin E, Ciavarella C, Cuomo-Dannenburg G, Barzon L, Del Vecchio C et al (2020) Suppression of a SARSCoV-2 outbreak in the Italian municipality of Vo'. Nature 584(August):425-429

5. Viner RM, Mytton OT, Bonell C, Melendez-Torres GJ, Ward J, Hudson L et al (2020) Susceptibility to SARS-CoV-2 infection 
among children and adolescents compared with adults: a systematic review and meta-analysis. JAMA Pediatr 1-14

6. Bi Q, Wu Y, Mei S, Ye C, Zou X, Zhang Z et al (2020) Epidemiology and transmission of COVID-19 in 391 cases and 1286 of their close contacts in Shenzhen, China: a retrospective cohort study. Lancet Infect Dis 20(8):911-919

7. Dong Y, Dong Y, Mo X, Hu Y, Qi X, Jiang F et al (2020) Epidemiology of COVID-19 among children in China. Pediatr 145(6)

8. Fernandes DM, Oliveira CR, Guerguis S, Eisenberg R, Choi J, Kim M et al (2020) SARS-CoV-2 clinical phenotypes and predictors of disease severity in hospitalized children and youth. $\mathrm{J}$ Pediatr [Internet] Available from: http://www.ncbi.nlm.nih.gov/ pubmed/33197493

9. Riphagen S, Gomez X, Gonzalez-Martinez C, Wilkinson N, Theocharis P (2020) Hyperinflammatory shock in children during COVID-19 pandemic. Lancet [Internet] 395(10237):1607-1608. Available from: https://doi.org/10.1016/S0140-6736(20)31094-1

10. Manson JJ, Crooks C, Naja M, Ledlie A, Goulden B, Liddle T et al (2020) COVID-19-associated hyperinflammation and escalation of patient care: a retrospective longitudinal cohort study. Lancet Rheumatol [Internet] 2(10):e594-602. Available from: https://doi. org/10.1016/S2665-9913(20)30275-7

11. World Health Organ (2020) Multisystem inflammatory syndrome in children and adolescents with COVID-19 1-3. Available from: https://www.who.int/publications/i/item/multisystem-inflammatorysyndrome-in-children-and-adolescents-with-covid-19

12. Moraleda C, Serna-Pascual M, Soriano-Arandes A et al (2021) Multi-inflammatory syndrome in children related to SARS-CoV-2 in Spain. Clin Infect Dis 4;72(9):e397-e401. https://doi.org/10. 1093/cid/ciaa1042

13. Harris PA, Taylor R, Thielke R, Payne J, Gonzalez N, Conde JG (2009) Research electronic data capture (REDCap) — a metadatadriven methodology and workflow process for providing translational research informatics support. J Biomed Inform [Internet] 42(2):377-381. Available from: https://doi.org/10.1016/j.jbi. 2008.08.010

14. ACLS Medical Training. Normal values in children. https://www. aclsmedicaltraining.com/normal-values-in-children/ Last Consulted, May 20th, 2021

15. Thiele C, Hirschfeld G (2020) Package cutpointr: improved estimation and validation of optimal cutpoints in R. Version 1.0.32. ; Available from: http://arxiv.org/abs/2002.09209

16. Villanuev RA, Chen ZJ, Wickham H (2016) ggplot2: elegant graphics for data analysis. In: Springer-Verlag New York
17. Goodrich B, Gabry J AI\& BS (2020) rstanarm: Bayesian applied regression modeling via Stan. In: R package version 2211

18. Swann OV, Holden KA, Turtle L, Pollock L, Fairfield CJ, Drake TM et al (2020) Clinical characteristics of children and young people admitted to hospital with COVID-19 in United Kingdom: prospective multicentre observational cohort study. BMJ 370:1-15

19. Wang S, Fu L, Huang K, Han J, Zhang R, Fu Z (2020) Neutrophilto-lymphocyte ratio on admission is an independent risk factor for the severity and mortality in patients with coronavirus disease 2019. J Infect

20. Giamarellos-Bourboulis EJ, Netea MG, Rovina N, Akinosoglou $\mathrm{K}$, Antoniadou A, Antonakos N et al (2020) Complex immune dysregulation in COVID-19 patients with severe respiratory failure. Cell Host Microbe [Internet] 27(6):992-1000 e3. Available from: https://doi.org/10.1016/j.chom.2020.04.009

21. Kamrath C, Mönkemöller K, Biester T, Rohrer TR, Warncke K, Hammersen J, Holl RW (2020) Ketoacidosis in children and adolescents with newly diagnosed type 1 diabetes during the COVID19 pandemic in Germany. JAMA 324(8):801-804

22. Zachariah P, Johnson CL, Halabi KC, Ahn D, Sen AI, Fischer A et al (2020) Epidemiology, clinical features, and disease severity in patients with coronavirus disease 2019 (COVID-19) in a children's hospital in New York City. New York JAMA Pediatr 174(10): $1-7$

23. Lishman J, Kohler C, de Vos C, van der Zalm MM, Itana J, Redfern A et al (2020) Acute appendicitis in multisystem inflammatory syndrome in children with COVID-19. Pediatr Infect Dis J Publish Ah(12):472-473

24. Stewart DJ, Hartley JC, Johnson M, Marks SD, du Pré P, Stojanovic J (2020) Renal dysfunction in hospitalised children with COVID-19. Lancet Child Adolesc Heal 4(8):e28-e29

25. Vasconcelos MK, Epalza C, Renk H, Tagarro A, Bielicki JA (2020) Harmonisation preserves research resources. Lancet Infect Dis [Internet] 3099(20):30585. Available from: https://doi.org/10. 1016/S1473-3099(20)30585-5

26. Price-Haywood EG, Burton J, Fort D, Seoane L (2020) Hospitalization and mortality among black patients and white patients with COVID-19. N Engl J Med 382(26):2534-2543

Publisher's Note Springer Nature remains neutral with regard to jurisdictional claims in published maps and institutional affiliations.

\title{
Authors and Affiliations
}

\begin{abstract}
Alfredo Tagarro ${ }^{1,2,3}(\mathbb{D})$ Elena Cobos-Carrascosa ${ }^{2} \cdot$ Serena Villaverde $^{2} \cdot$ Francisco-Javier Sanz-Santaeufemia $^{4}$. Carlos Grasa $^{5}$ - Antoni Soriano-Arandes ${ }^{6} \cdot$ Alicia Hernanz $^{7}$ - María Luisa Navarro ${ }^{7}$. Rosa Pino ${ }^{8}$. Cristina Epalza ${ }^{2,9}$. Rosa Batista ${ }^{1}$. Jana Rizo ${ }^{1}$. María-Isabel Iglesias-Bouzas ${ }^{10}$. Paula Rodríguez-Molino ${ }^{5}$. Sara Villanueva-Medina ${ }^{9}$. Jaime Carrasco-Colom ${ }^{9}$. José-Antonio Alonso-Cadenas ${ }^{4} \cdot$ María-José Mellado $^{5}$. Blanca Herrero ${ }^{4}$. Susana Melendo ${ }^{6} \cdot$ Mercedes De La Torre $^{4} \cdot$ Lourdes Calleja $^{4}$. Cristina Calvo ${ }^{5}$ María Urretavizcaya-Martínez ${ }^{11}$. Itziar Astigarraga ${ }^{12}$. Ana Menasalvas ${ }^{13} \cdot$ María Penin $^{14}$. Olaf Neth ${ }^{15} \cdot$ Arantxa Berzosa $^{16} \cdot$ María De Ceano-Vivas $^{17}$. Paula Vidal ${ }^{18}$ - Isabel Romero ${ }^{19} \cdot$ Raúl González $^{20}$ - María Luz García ${ }^{21}$ - Juan-Miguel Mesa ${ }^{1}$. Álvaro Ballesteros ${ }^{2}$. María Bernardino ${ }^{1} \cdot$ Cinta Moraleda ${ }^{2,9}$. EPICO-AEP Working Group
\end{abstract}

Elena Cobos-Carrascosa

Elena.cobos@gmail.com

Serena Villaverde

serenavillaverde@outlook.es

Francisco-Javier Sanz-Santaeufemia sanzsantaeufemiafj@gmail.com
Carlos Grasa

carlosgrasa@gmail.com

Antoni Soriano-Arandes

tsorianoarandes@gmail.com

Alicia Hernanz

h.lobo.alicia@gmail.com 
María Luisa Navarro

marisa.navarro.gomez@gmail.com

Rosa Pino

rpino@sjdhospitalbarcelona.org

Cristina Epalza

crepalza@hotmail.com

Rosa Batista

rangela.batista@salud.madrid.org

Jana Rizo

jrizo.hrc@salud.madrid.org

María-Isabel Iglesias-Bouzas

mabigl@yahoo.com

Paula Rodríguez-Molino

paularmolino@gmail.com

Sara Villanueva-Medina

s.villanuevamedina@gmail.com

Jaime Carrasco-Colom

jcarrascocolom@gmail.com

José-Antonio Alonso-Cadenas

jalonsocadenas@gmail.com

María-José Mellado

mariajose.mellado@salud.madrid.org

Blanca Herrero

blanca.herrero@hotmail.com

Susana Melendo

smelendo@vhebron.net

Mercedes De La Torre

mtorrespi@ono.com

Lourdes Calleja

mismisimalou@gmail.com

Cristina Calvo

ccalvorey@gmail.com

María Urretavizcaya-Martínez

mariaurretavizcaya@hotmail.com

Itziar Astigarraga

mariaiciar.astigarragaaguirre@ osakidetza.eus

Ana Menasalvas

amenasalvas@hotmail.com

María Penin

mariapenin@yahoo.es

Olaf Neth

olafneth@gmail.com

Arantxa Berzosa

aranire@msn.com

María De Ceano-Vivas

mceanovivas@yahoo.es

Paula Vidal

pauuv.810@gmail.com

Isabel Romero

iromero@hmhospitales.com

Raúl González

gonzalez_rau@gva.es
María Luz García

marialuz.hso@gmail.com

Juan-Miguel Mesa

juanmiguelmesa@hotmail.com

Álvaro Ballesteros

a.ballesteros.h12o@gmail.com

María Bernardino

maria.bernardino.96@hotmail.com

Cinta Moraleda

maria.bernardino.96@hotmail.com

1 Paediatrics Department, Paediatrics Research Group, Hospital Universitario Infanta Sofía, Universidad Europea de Madrid, Madrid, Spain

2 Fundación de Investigación Biomédica Hospital 12 de Octubre, Instituto de Investigación 12 de Octubre (imas12), RITIP (Translational Research Network in Paediatric Infectious Diseases), Madrid, Spain

3 Pediatrics Department, Hospital Universitario Infanta Sofía, Madrid, Spain

4 Paediatrics Department, Hospital Universitario Niño Jesús, Madrid, Spain

5 Paediatrics, Infectious and Tropical Diseases Department, Hospital Universitario La Paz, RITIP (Translational Research Network in Paediatric Infectious Diseases), Instituto Investigación Hospital La Paz (IDIPaz), Madrid, Spain

6 Infectious Diseases and Paediatric Immunology Unit, Department of Paediatrics, Hospital Universitario Vall d'Hebron, Barcelona, Spain

7 Paediatric Infectious Diseases Unit, Department of Paediatrics, Hospital Universitario Gregorio Marañón, Madrid, Spain

8 Paediatric Infectious Diseases Unit, Department of Paediatrics, Hospital Universitario Sant Joan de Deu Barcelona, Barcelona, Spain

9 Paediatric Infectious Diseases Unit, Department of Paediatrics, Paediatric Research and Clinical Trials Unit (UPIC), Hospital Universitario 12 de Octubre, Madrid, Spain

10 Paediatric Intensive Care Unit, Hospital Universitario Niño Jesús, Madrid, Spain

11 Paediatrics Department, Complejo Hospitalario de Navarra, Pamplona, Spain

12 Department of Pediatrics, Hospital Universitario Cruces, Biocruces Bizkaia Health Research Institute, University of the Basque Country UPV/EHU, OsakidetzaBarakaldo, Spain

13 Paediatrics Department, Hospital Universitario Virgen de La Arrixaca, Murcia, Spain

14 Paediatrics Department, Hospital Príncipe de Asturias, Alcalá de Henares, Madrid, Spain

15 Paediatrics Department, Hospital Universitario Virgen del Rocío, Sevilla, Spain

16 Paediatrics Department, Hospital Universitario Clínico San Carlos, Madrid, Spain 
17 Emergency Pediatrics Department, Hospital Universitario La Paz, Instituto Investigación Hospital La Paz (IDIPaz), Madrid, Spain

18 Paediatrics Department, Hospital Universitario Lozano Blesa, Zaragoza, Spain

19 Paediatrics Department, Hospitales HM, Madrid, Spain
20 Paediatrics Department, Hospital Universitario Sant Joan, Comunidad Valenciana, AlacantAlicante, Spain

21 Paediatrics Department, Hospital Universitario Severo Ochoa, Leganés, Madrid, Spain 